\title{
INFLUENCE OF DIETARY BETAINE ON NUTRIENT UTILIZATION AND DIGESTIVE ENZYME ACTIVITY IN YELLOW-FEATHER BROILERS DURING STARTER PHASE
}

\author{
W.C. Liu, B.H. Ou, Y.L. Yuan, C.Y. Sun, M. Xiao, Z.H. Zhao ${ }^{*}$ and L.L. An ${ }^{*}$ \\ Department of Animal Science, College of Agriculture, Guangdong Ocean University, Zhanjiang, Guangdong 524088, \\ P. R. China \\ *Corresponding author's email: zhzhao@gdou.edu.cn; anlilong gdou@163.com. \\ https://doi.org/10.36899/JAPS.2020.1.0029 \\ Published online January 02, 2020
}

\begin{abstract}
The present experiment was conducted to investigate the effects of dietary supplementation with different levels of betaine on nutrient utilization and digestive enzyme activity in indigenous yellow-feather broilers during starter phase. A total of 288 male, one-d-old Huaixiang chickens with an average initial body weight (BW) of $44.52 \pm 1.07 \mathrm{~g}$ were randomly allotted to 4 treatments. Each dietary treatment consisted of 6 replicates, with 12 birds per replicate. The 4 dietary treatments were corn-soybean meal-based diets and supplemented with $0,500,1000$ and $2000 \mathrm{mg} / \mathrm{kg}$ betaine, respectively. The trial period lasted $28 \mathrm{~d}$. It was found that dietary betaine supplementation improved the calcium $(\mathrm{Ca})$ utilization (cubic, $\mathrm{P}=0.0187$ ). Meanwhile, dietary supplementation with different levels of betaine increased the trypsin activity (quadratic, $\mathrm{P}=0.0445$ ) and lipase activity (cubic, $\mathrm{P}=0.0344$ ) of the jejunum. Taken together, this study revealed that betaine could promote the digestive function in indigenous yellow-feather broilers during starter phase.
\end{abstract}

Keywords: betaine; digestive function; indigenous yellow-feather broilers; starter phase.

\section{INTRODUCTION}

Yellow-feather broilers are increasingly favored by consumers because of their good meat quality. Huaixiang chicken is a famous indigenous yellow-feather broiler breed in South China (Shi et al., 2016). Because of the young broilers' intestinal development is imperfect and the low resistance, sub therapeutic antibiotics are widely used in young broilers diets to improve the gut health and promote the growth performance (Liu and Kim, 2017). However, prohibition of sub therapeutic antibiotic usage in animal feed is a current global trend, and the interest in searching alternatives to sub therapeutic antibiotics in feed has increased. It is well known that the natural active substances, including probiotics, prebiotics, enzymes and plant extracts, which could be used as potential alternatives to sub therapeutic antibiotics (Liu et al., 2018).

Betaine is a trimethyl derivative of glycine and known to have two major roles in the body, as a methyl group donor and an organic osmolyte (Rao et al., 2011). On the other hand, betaine has been shown to protect cells from osmotic stress and allow them to continue regular metabolic activities in conditions that would normally inactivate the cell (Hamidi et al., 2010). Previous studies indicated that betaine supplementation as feed additives plays important roles such as improving growth performance, immune response and nutrients digestibility in broilers (Eklund et al., 2005; Attia et al., 2009; He et al., 2015; Shakeri et al., 2018; Liu et al.,
2019). However, few studies focused on the effects of betaine on nutrient utilization and digestive enzyme activity in young yellow-feather broilers. Therefore, the present experiment was conducted to evaluate the effects of betaine supplementation on nutrient utilization and digestive enzyme activity in Chinese indigenous yellowfeather broilers during starter phase.

\section{MATERIALS AND METHODS}

Birds, Diets and Experimental Procedures: A total of 288 male, one-d-old Huaixiang chickens (Chinese indigenous yellow-feather broilers) with an average initial BW of $44.52 \pm 1.07 \mathrm{~g}$ were obtained from a local hatchery, and randomly distributed to 4 treatments. Each dietary treatment consisted of 6 replicate cages, with 12 birds per replicate. All birds were raised in stainless steel pens with concrete floors in an environmentally controlled house. The experimental period is $28 \mathrm{~d}$. Ingredient composition and nutrient content of basal diets for both experimental phases are presented in Table 1. Basal diets were formulated to meet or exceed Chinese indigenous yellow feather broilers recommendations based on Chinese Chicken Feeding Standard (NY/T332004). The 4 dietary treatments were corn-soybean mealbased diets and supplemented with 0, 500, 1000 and 2000 $\mathrm{mg} / \mathrm{kg}$ betaine, respectively. The betaine was obtained from Shandong Jianchuan Biotechnology Co., Ltd. (The purity is $99 \%$, Shandong, China). Diets were given to the birds in mash form. Birds had free access to feed and 
water. Lighting was continuous, and room temperature was maintained at $33 \pm 1{ }^{\circ} \mathrm{C}$ for the first $3 \mathrm{~d}$, and then gradually reduced by $2{ }^{\circ} \mathrm{C}$ a week until reaching $24{ }^{\circ} \mathrm{C}$. The relative humidity is controlled at $60 \%$ during the feeding trial.

Sampling and Measurements: After the $28 \mathrm{~d}$ feeding trial, one bird from each replicate was randomly selected and moved to metabolic cages for metabolic test. Determination of nutrient metabolism using total excreta collection method. The metabolic test was lasted 4 days. During the test, feed intake and excrements were recorded, and the excreta were all collected. The crude protein, ash, energy, calcium (Ca) and phosphorus (P) contents in the feed and excreta were then analyzed. The nutrient utilization rate was calculated by the following formula:

Apparent nutrient utilization rate $(\%)=($ feed intake $\times \mathrm{Nf}$ - amount of excretion $\times \mathrm{Ne}) /$ feed intake $\times$ Nf) $\times 100$.

where $\mathrm{Ne}=$ nutrient concentration in excreta $(\%$ $\mathrm{DM}), \mathrm{Nf}=$ nutrient concentration in feed (\% DM).

At the end of the experiment (d 28), 6 birds (1 bird per cage) were randomly selected from each treatment were weighted and then killed by cervical dislocation. The digesta of duodenum, jejunum and ileum were collected at $2 \mathrm{~g}$. The digestive enzyme activity of digesta from the duodenum, jejunum and ileum were detected by using commercial kit (Nanjing Jiancheng Bioengineering Institute, Nanjing, China).

Statistical Analysis: All data were analyzed using GLM procedure of SAS 9.4 (SAS Institute Inc., Cary, NC). Orthogonal polynomial contrasts were used to test the linear, quadratic and cubic effects of the increasing levels of dietary betaine. Variability in data was expressed as standard error of means (SEM) and $\mathrm{P} \leq 0.05$ was considered to be statistically significant.

\section{RESULTS AND DISCUSSION}

The results of nutrient utilization and digestive enzyme activity were described in Table 2 and 3 . At the end of the experiment, with increasing the dietary betaine levels from 0 to $2000 \mathrm{mg} / \mathrm{kg}$, the $\mathrm{Ca}$ utilization was improved (cubic, $\mathrm{P}=0.0187$ ). In addition, dietary supplementation with different levels of betaine increased the trypsin activity (quadratic, $\mathrm{P}=0.0445$ ) and lipase activity (cubic, $\mathrm{P}=0.0344$ ) of the jejunum.

Young broilers growth faces many challenges because the low resistance and digestive physiology of young chicks is low developed (Yan et al., 2017). The present study demonstrated for the first time that betaine could act as a digestive function promoter for indigenous yellow-feather broilers during starter phase. These findings are in agreement with the reports from Eklund et al. (2005), who revealed that dietary supplementation of betaine improves the digestibility of specific nutrients, such as methionine, protein and crude fat. However, few other researchers investigated the effects of betaine on nutrient utilization and digestive enzyme activity in broilers, thus no more comparisons could be made. A study in rats carried by Wang et al., (2018), who demonstrated that betaine supplementation markedly increased the activities of amylase, trypsin, lipase and chymotryps in the small intestine. Our observation and the reports from related studies for nutrient utilization and digestive enzyme activity in the betaine-treated broilers supported the idea that betaine was associated with antioxidant and methyl donor properties through its involvement in cell membrane stabilisation (Alirezaei et al., 2012). Also, Wang et al., (2018) suggested that betaine could increase the activity of key cellular enzymes so as to improve the digestive enzyme activity. On the other hand, the increased nutrient utilization and digestive enzyme activity might be associated with the improved intestinal morphology. In this regard, Kettunen et al., (2001) found that dietary betaine supplementation increased the intestinal epithelial villus-crypt ratio in broilers, thus promoting the functional digestive parameters, and they thought the improved gut health and digestive function was due to both the methyl group donor nature and the osmotic nature of betaine. Finally, it was assumed that gut microbiota also contributed to the intestinal health and digestion physiology (Liu and Kim, 2017). Therefore, betaine might be involved in the gut microbiota and then improved the nutrient utilization and digestive enzyme activity. However, the underlying mechanism is not quite clear yet and need to be verified by further studies.

Table 1. Basal diet composition (as-fed basis).

\begin{tabular}{lc}
\hline Item & Contents (\%) \\
\hline Ingredients & \\
Corn & 60.99 \\
Soybean meal & 29.00 \\
Wheat bran & 2.16 \\
Fish meal & 3.00 \\
Soybean oil & 2.00 \\
Limestone & 1.28 \\
CaHPO & 1.26 \\
Premix & 0.31 \\
Total & 100.00 \\
Calculated nutrient levels & \\
ME (MJ/kg) & 12.30 \\
Crude protein (\%) & 20.03 \\
Ca (\%) & 1.00 \\
Met $(\%)$ & 0.45 \\
Lys (\%) & 1.09 \\
Phosphorus (\%) & 0.68 \\
\hline
\end{tabular}

${ }^{1}$ Premix Provided per kilogram of diet: 5,000 IU of vitamin A, $1000 \mathrm{IU}$ of vitamin $\mathrm{D}_{3}, 10 \mathrm{IU}$ of vitamin $\mathrm{E}, 0.5 \mathrm{mg}$ of vitamin 
$\mathrm{K}_{3}, 3 \mathrm{mg}$ of thiamin, $7.5 \mathrm{mg}$ of riboflavin, $4.5 \mathrm{mg}$ of vitamin $\mathrm{B}_{6}$, $10 \mu \mathrm{g}$ of vitamin $\mathrm{B}_{12}, 25 \mathrm{mg}$ of niacin, $0.55 \mathrm{mg}$ of folic acid, 0.2 $\mathrm{mg}$ of biotin, $500 \mathrm{mg}$ of choline, and $10.5 \mathrm{mg}$ of pantothenic acid. $60 \mathrm{mg}$ of $\mathrm{Zn}, 80 \mathrm{mg}$ of $\mathrm{Mn}, 80 \mathrm{mg}$ of $\mathrm{Fe}, 3.75 \mathrm{mg}$ of $\mathrm{Cu}$, and $0.35 \mathrm{mg}$ of $\mathrm{I}$.

Table 2. Influence of dietary betaine on nutrient utilization in indigenous yellow-feather broilers during starter phase.

\begin{tabular}{lcccccccc}
\hline \multirow{2}{*}{ Items, \% } & \multicolumn{3}{c}{ Dietary betaine levels $\mathbf{( m g} / \mathbf{k g})$} & \multirow{2}{*}{ Pevalue } \\
\cline { 2 - 4 } & $\mathbf{0}$ & $\mathbf{5 0 0}$ & $\mathbf{1 0 0 0}$ & $\mathbf{2 0 0 0}$ & & Linear & Quadratic & Cubic \\
\hline Crude protein & 66.56 & 67.08 & 62.66 & 67.52 & 3.49 & 0.9225 & 0.5437 & 0.3763 \\
Ash & 44.37 & 53.44 & 44.09 & 46.24 & 3.21 & 0.7983 & 0.2978 & 0.0545 \\
Energy & 82.29 & 82.76 & 81.29 & 81.88 & 1.02 & 0.5664 & 0.9532 & 0.3961 \\
Ca & 60.70 & 62.81 & 58.51 & 62.13 & 1.22 & 0.9964 & 0.5435 & $\mathbf{0 . 0 1 8 7}$ \\
P & 57.89 & 58.51 & 54.49 & 55.10 & 2.72 & 0.3252 & 0.9990 & 0.4582 \\
\hline
\end{tabular}

SEM, Standard error of means.

Table 3. Influence of dietary betaine on digestive enzyme activity in indigenous yellow feather broilers during starter phase.

\begin{tabular}{|c|c|c|c|c|c|c|c|c|}
\hline \multirow{2}{*}{ Items, U/mg prot } & \multicolumn{4}{|c|}{ Dietary betaine levels (mg/kg) } & \multirow{2}{*}{ SEM } & \multicolumn{3}{|c|}{ P-value } \\
\hline & $\mathbf{0}$ & 500 & 1000 & 2000 & & Linear & Quadratic & Cubic \\
\hline \multicolumn{9}{|l|}{ Duodenum } \\
\hline Trypsin & 245.04 & 259.38 & 197.90 & 114.00 & 48.88 & 0.0551 & 0.3309 & 0.8103 \\
\hline Lipase & 24.27 & 26.27 & 21.34 & 11.03 & 11.64 & 0.4045 & 0.6043 & 0.9765 \\
\hline \multicolumn{9}{|l|}{ Jejunum } \\
\hline Trypsin & 250.30 & 369.00 & 518.50 & 267.40 & 84.33 & 0.6025 & 0.0445 & 0.2703 \\
\hline Lipase & 4.08 & 4.07 & 3.12 & 4.21 & 0.29 & 0.6800 & 0.0770 & 0.0344 \\
\hline \multicolumn{9}{|l|}{ Ileum } \\
\hline Trypsin & 292.82 & 285.31 & 269.63 & 280.60 & 22.38 & 0.6085 & 0.6855 & 0.7329 \\
\hline Lipase & 1.97 & 1.27 & 2.09 & 0.88 & 0.44 & 0.2338 & 0.5703 & 0.0909 \\
\hline
\end{tabular}

SEM, Standard error of means.

Conclusion: In summary, dietary supplementation with betaine in indigenous young yellow-feather broilers diets improved the Ca utilization, and showed positive effects on trypsin activity and lipase activity of the jejunum. Further studies are necessary to confirm the conclusions and to illustrate the underlying mechanism.

Authors' Contribution: WC Liu and LL An conceived and designed the study. CY Sun and BH Ou performed experimental work and laboratory analysis. M Xiao and ZZ Zhao helped in preparation of the manuscript. WC Liu analyzed the data and wrote the article, WC Liu, YL Yuan and ZH Zhao revised the manuscript.

Acknowledgments: This research was funded by Natural Science Foundation of Guangdong Province (2018A030307023); Innovative Strong School Engineering Youth Talent Project (2017KQNCX090) and Key Platform Projects (2018302) by Department of Education in Guangdong Province; Talent Research Start-up Project of Guangdong Ocean University (R18007); Students Innovation Training (CXXL2019052) and Pandeng Program (pdjh2019b0234) of Guangdong Province.

Conflicts Of Interest: The authors declare they have no conflict of interest.

\section{REFERENCES}

Alirezaei, M., G.H. Reza, V.R. Ranjbar, and A. Hajibemani (2012). Betaine: a promising antioxidant agent for enhancement of broiler meat quality. Br. Poult. Sci. 53(5):699-707.

Attia, Y.A., R.A. Hassan and E.M.A. Qota (2009). Recovery from adverse effects of heat stress on slow-growing chicks in the tropics 1: Effect of ascorbic acid and different levels of betaine. Trop. Anim. Health Pro. 41(5):807-818.

Eklund, M., E. Bauer, J. Wamatu, and R. Mosenthin (2005). Potential nutritional and physiological functions of betaine in livestock. Nutr. Res. Rev. 18(1):31-48. 
Hamidi, H., R. Jahanian, and J. Pourreza (2010). Effect of dietarybetaine on performance, immune competence and gut contents osmolarity of broilers challenged with a mixedcoccidial infection. Asian J. Anim. Vet. Adv. 5:193-201.

He, S., S. Zhao, S.F. Dai, D. Liu, and S.G. Bokhari (2015). Effects of dietary betaine on growth performance, fat deposition and serum lipids in broilers subjected to chronic heat stress. Anim. Sci. J. 86(10):897-903.

Kettunen, H., K. Tiihonen, S. Peuranen, M.T. Saarinen, and J.C. Remus (2001). Dietary betaine accumulates in the liver and intestinal tissue and stabilizes the intestinal epithelial structure in healthy and coccidia-infected broiler chicks. Comp. Biochem. Phys. A. 130(4):759-769.

Liu, W.C., and I.H. Kim (2017). Effects of dietary xylanase supplementation on performance and functional digestive parameters in broilers fed wheat-based diets. Poult. Sci. 96(3):566-573.

Liu, W.C., M. Ye, J.H. Liao, Z.H. Zhao, I.H. Kim, and L.L. An (2018). Application of complex probiotics in swine nutrition- A review. Ann. Anim. Sci. 18(2):335-350.

Liu, W.C., Y.L. Yuan, C.Y. Sun, B. Balasubramanian, Z.H. Zhao, and L.L. An (2019). Effects of betaine on growth performance, digestive function, carcass traits, and meat quality in indigenous yellow-feathered broilers under longterm heat stress. Animals 9(8):506.
Rao, S., M. Raju, A. Panda, P. Saharia, and G.S. Sunder(2011). Effect of supplementing betaine on performance, carcass traits and immune responses in broiler chicken fed diets containing different concentrations of methionine. Asian Austral. J. Anim. Sci. 24(5):662-669.

Shakeri, M., J.J. Cottrell, S. Wilkinson, M. Ringuet, J.B. Furness, and F.R. Dunshea (2018). Betaine and antioxidants improve growth performance, breast muscle development and ameliorate thermoregulatory responses to cyclic heat exposure in broiler chickens. Animals 8(10): 162.

Shi, J.Z., W.Y. Guan, Y.M. Wang, and B.W. Du(2016). Xinyi Huaixiang chicken growth and meat performance test results. Contemp. Anim. Husbandry 24(20):35-39.

Wang, H.C., S.S. Li, S.L. Fang, X.J. Yang, and J. Feng (2018). Betaine improves intestinal functions by enhancing digestive enzymes, ameliorating intestinal morphology, and enriching intestinal microbiota in high-salt stressed rats. Nutrients 10(7):907.

Yan, F., J.J. Dibner, C.D. Knight, and M. Vazquez-Anon (2017). Effect of carbohydrase and protease on growth performance and gut health of young broilers fed diets containing rye, wheat, and feather meal. Poult. Sci. 96(4):817-828. 